\title{
Composite chitosan/polyethylene oxide film for duraplasty in traumatic brain injury model in rats
}

\author{
Panteleichuk A. ${ }^{1}$, Kadzhaya M. ${ }^{1}$, Biloschytsky V. ${ }^{2}$, Shmeleva A. ${ }^{3}$, Petriv T. ${ }^{4}$, Gnatyuk O. ${ }^{5}$, Dovbeshko G. ${ }^{5}$, Kozakevych R. ${ }^{6}$, Tyortyh V. \\ ${ }^{1}$ Department of neurotrauma, Romodanov State Institute of Neurosurgery of the National Academy of Medical Sciences of Ukraine, \\ Kyiv, Ukraine \\ ${ }^{2}$ Chronic pain treatment group, Romodanov State Institute of Neurosurgery of the National Academy of Medical Sciences of Ukraine, \\ Kyiv, Ukraine \\ ${ }^{3}$ Department of Neuropatomorphology, Romodanov State Institute of Neurosurgery of the National Academy of Medical Sciences \\ of Ukraine, Kyiv, Ukraine \\ ${ }^{4}$ Department of Reconstructive Neurosurgery with X-ray surgery, Romodanov State Institute of Neurosurgery of the National Academy \\ of Medical Sciences of Ukraine, Kyiv, Ukraine \\ ${ }^{5}$ Institute of Physics of the National Academy of Sciences of Ukraine, Kyiv, Ukraine \\ ${ }^{6}$ Chuiko Institute of Surface Chemistry of the National Academy of Sciences of Ukraine, Kyiv, Ukraine
}

e-mail: basirovich@ukr.net

\section{ABSTRACT}

The duraplasty is a standard procedure during neurosurgery for injuries and diseases of the brain. The hermetic closure of the dura mater is not always possible with the application of autologous tissues. Synthetic, allogeneic and xenogeneic implants, which are currently used, have disadvantages, so the search for the material that would best meet the requirements for a dura mater scaffold continues.

THE PURPOSE is to study the physical and chemical properties of the composite chitosan/polyethylene oxide (PEO) film and determine the effectiveness of its application for duraplasty in the experiment in vivo; to analyze its ability to biodegradation; to evaluate the effect of chitosan/PEO scaffold on the regeneration of dura matter.

MATERIALS AND METHODS. The experiment used 10 white rats aged 12 months with a penetrating traumatic brain injury model. Postoperative material was examined by macroscopy, optical microscopy and infrared spectroscopy.

RESULTS. According to the analysis of infrared absorption, spectral markers of scar tissue, regenerating and intact dura mater were determined. Oscillation spectroscopy data indicate degradation of the chitosan film and repair of normal dura mater. Histology data also indicate biological degradation of the chitosan film and its replacement by newly formed normal connective tissue.

CONCLUSION. The data of morphological and spectroscopic studies show the ability of chitosan/PEO film to biodegradation in vivo with followed replacement not by scar but by normal connective tissue.

KEY WORDS: chitosan; polyethylene oxide; penetrating traumatic brain injury; infrared spectroscopy; morphological studies

In neurosurgery, the problem of the duraplasty is extremely urgent, because one of the conditions for success in neurosurgical intervention is to restore integrity of dura mater (DM) and the subdural space to prevent damage to cerebral cortex and the leakage of cerebrospinal fluid [1]. Hermetic closure of the dura mater correlates with a decrease in the intensity of liquorrhea and a decrease in the rate of infectious complications [2, 3]. This issue is especially urgent after the decompression trepanation due to severe traumatic brain injury or acute cerebrovascular accident [4 5]; surgery on the skull and posterior fossa, when DM defect is created as a result of bipolar coagulation; the dural resection following meningioma surgery [6], as well as spinal neurosurgery [7]. In this case, there is a need to application a dura mater scaffold.

The study of DM substitutes has been continuing for over a century. In 1924, W. Penfield proposes the concept of «ideal dura mater substitute» $[8,9]$ which was further developed, for example in the work of 0 . Arutyunov, N. Meskhia [10]. The substitute must be non-toxic, biodegradable, and suitable for suturing; not lead to commissure or infection; create a waterproof barrier; to have antibacterial properties at penetrating trauma; 

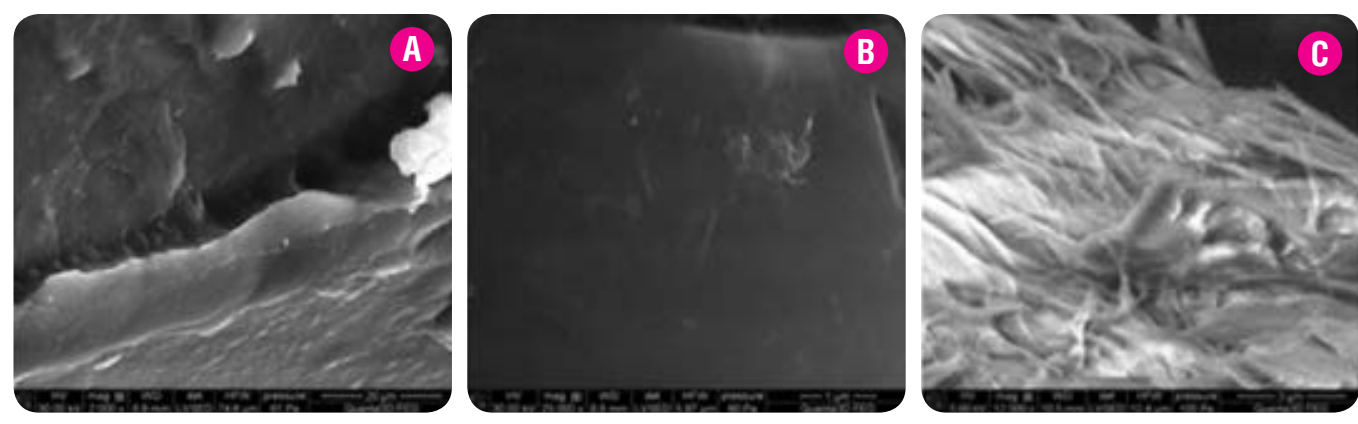

and should be at a reasonable price $[11,12]$. The development of modern new polymeric materials stimulates the search for new opportunities in creating an effective substitute for DM [11].

To improve the dural closure, various materials of autologous, allogeneic, xenogeneic and synthetic origin were tested [12-14]. Autologous grafts are non-toxic, quickly integrated in host tissues, flexible, durable and easily sutured [15-17]. However, the lack of the available autografts and needs to additional incisions to obtain it limit their application [14] The feasibility of using allograft tissue was reviewed following the publication of reports linking dura mater transplantation to Creutzfeldt-Jakob disease (transmissible spongiform encephalopathy) [10]. Thus, xenogeneic and synthetic materials become an alternative to neurosurgery.

One of the promising materials for the development of a xenogeneic substitute for DM may be chitosan. It is biodegradable, non-toxic, has antibacterial and antifungal properties [18] and is, therefore, considered promising to create an effective scaffold for DM [13].

Several techniques have been proposed for the design of DM substitute based on chitosan. Chitosan as a biopolymer allows to create twolayer membranes with porous and non-porous parts. This model of chitosan is similar in thickness, structural and functional characteristics to DM and has greater tensile strength than the collagen matrix. The feasibility of creating a two-layer chitosan matrix is as follows: (a) in the porous part, growth factors can penetrate through the pore network, cell migration and neovascularization occur, but this layer is unstable to mechanical loads; (b) the non-porous part provides greater resistance to loads, it can be sutured [13]

To improve the structural and mechanical properties of chitosan materials, researches aimed at developing various composite systems based on chitosan and other polymers are promising [19]. A substitute for DM in the form of a grid of polylactic acid and chitosan was developed [20]. Wider and more efficient use of chitosan can be expected with the introduction of electrospinning to obtain nanofiber materials. Thin nanofibers can be obtained in the mixtures of chitosan with polyvinyl alcohol, gelatin or collagen, silk fibroin, polycaprolactone, polyethylene oxide (PE0) [21]. PEO has good spinnability, low toxicity and its interaction with chitosan improves the technical processing of the latter in the production of polymer films [21]. It is a biodegradable polymer [22]. PEO is approved for the use in drug delivery systems by the US Food and Drug Administration (FDA) [23]. Given the viability of the composite material of chitosan with PEO [24] with the possibility of adjusting a wide range of hydrophilic properties, physical and mechanical characteristics [21], we selected a model of dura mater substitute of xenogeneic (chitosan) and synthetic (polyethylene oxide) origin for our study.

PURPOSE - to investigate the physical and chemical properties of the composite chitosan/polyethylene oxide film and to determine the effectiveness of its application for duraplasty in animals; to analyze its ability to biodegradation; to evaluate the effect of this biopolymer film on the regeneration of dura mater.

\section{MATERIALS AND METHODS}

White rats were used in the study. The animals were kept in standard vivarium conditions under natural light-dark cycle and fed a balanced (Protocol \#18 of June 10, 2016). compound feed ad libitum. The surgery and the euthanasia of animals were performed according to the rules of bioethics regulated by Directive 2010/63/EU «On the protection of animals used for scientific purposes» (2010) and the Law of Ukraine \#3447-IV «On protection of animals from cruelty» (2006). The study was approved by the Committee on Bioethics of the Romodanov State Institute of Neurosurgery of the NAMS of Ukraine

Methods of surgery. Fifteen male rats aged 12 months and weighing 250-300 g were selected for surgery. After craniotomy and penetrating brain injury [25], duraplasty was performed with composite film based on chitosan/PEO. Experimental animals were divided into 3 groups $(n=5$ animals per group): (1) for histological examination; (2) for macroscopic and infrared (IR) spectroscopic examination; (3) a group of intact animals (the samples of native DM for IR spectroscopy). The surgery was performed under general anesthesia by xylazine (Sedazin, Biowet, Poland) $15 \mathrm{mg} / \mathrm{kg}$ and ketamine (Calipsol, Gedeon Richter, Hungary) $70 \mathrm{mg} / \mathrm{kg}$ body weight that was administered intramuscularly. After head shearing and disinfection with a Betadine $10 \%$ solution (Aegis, Hungary), a midline skin incision was performed and the bones of the skull were exposed. A $4 \times 7 \mathrm{~mm}$ trepanation hole was formed in the right parietal area using a high-speed drill. The bone flap was isolated from the underlying dura mater and removed. DM was carefully dissected crosswise from the middle of the hole to its corners. The surface of the brain was exposed and the cerebral cortex was penetrated with a G18 needle to a depth of $2 \mathrm{~mm}$.

Dural flaps were placed back without suturing with diastasis, covered with chitosan/polyethylene oxide film without bone flap. Thus, decompressive craniectomy was modeled. After hemostasis, the wound was sutured using Vicryl $5 / 0$ and treated with a Betadine solution. Postoperative antimicrobial prophylaxis using intramuscularly injection of Ceftriaxone $20 \mathrm{mg} / \mathrm{kg}$ was performed. Animals were euthanized on the $21^{\text {st }}$ day by decapitation under ketamine anesthesia $(0.1 \% 2 \mathrm{~mL})$.

Synthesis and selection of polymer composite films. Several variants of chitosan-based biopolymer films have been proposed for duraplasty: native film consists of $100 \%$ chitosan; composite chitosan/polyethylene oxide film with equal mass fractions of components chitosan/PEO $1 / 1$ wt $\%$, and composite chitosan/polyethylene oxide film with mass fraction of chitosan $70 \%$ (chitosan/PE0 7/3 wt\%). Synthesis and the following laboratory studies were performed at Chuiko Institute of Surface Chemistry.

Native and composite films were prepared by evaporation of the solvent after the coating the glass with a primary polymer solution. Primary solutions were prepared by dissolving chitosan, PEO in $2 \mathrm{wt} \%$ Acetic acid solutions using magnetic stirrer for 12 hours. After forming, the films were dried at room temperature for 12 hours. When the drying was completed, the film was placed in $1.0 \mathrm{M}$ sodium hydroxide solution for several hours to neutralize excess acetic acid, followed by intensive washing with distilled water. Thereafter the films were dried at room temperature for 24 hours. Subsequently, a thorough study of the structure of the obtained films, their water absorption capacity and spectral analysis were performed. The surface structure of the polymer composite films was examined using a Quan$\mathrm{ta}^{\mathrm{T} M}$ 3D FEG scanning electron microscope (FEI, USA) (Fig. 1).

Also, a laboratory study of the water absorption capacity of the dural substitutes was performed (Table 1). This is a very important parameter, because with a high degree of hydrophilicity of the DM scaffold, there may be a risk of brain compression [13]. 
SAMPLE

\begin{tabular}{l|l|}
\hline Chitosan & 230.34 \\
\hline Chitosan/PEO 1/1 wt\% & $140.3^{\star}$ \\
\hline Chitosan/PEO 7/3 wt\% & 150.92 \\
\hline
\end{tabular}

A Table 1. The water absorption capacity of polymer composites Note: * $-p<0.05$ compared to chitosan.

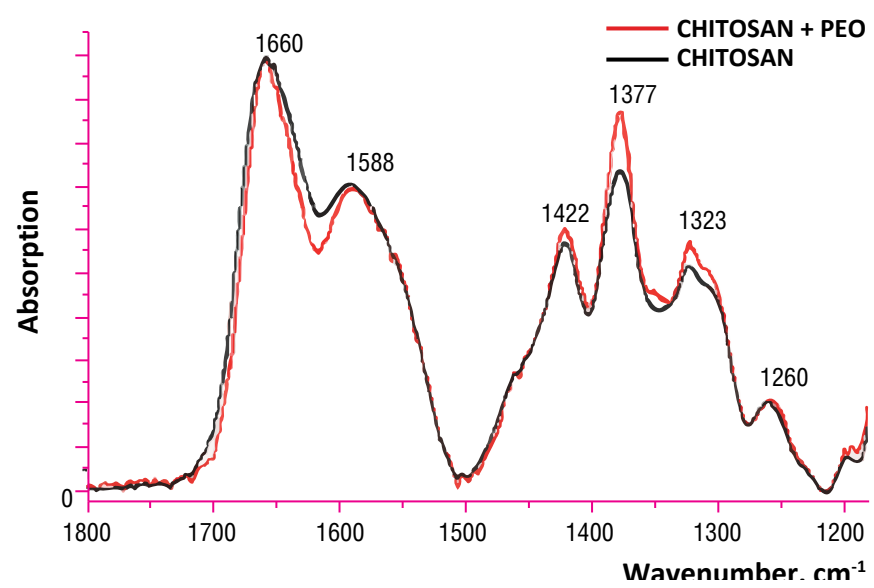

Fig. 2. FTIR spectra of films based on chitosan (black curve) and chitosan/PEO 7/3 wt\% (red curve).

\begin{tabular}{|c|l|}
\hline POINTS & \multicolumn{1}{c|}{ DESCRIPTION } \\
\hline $\mathbf{0}$ & There is no adhesion of scaffold to the cerebral cortex \\
\hline $\mathbf{1}$ & $\begin{array}{l}\text { Scaffold is fused with the cerebral cortex, but isolated } \\
\text { without macroscopic damage }\end{array}$ \\
\hline $\mathbf{2}$ & $\begin{array}{l}\text { Scaffold ingrow to the cortex, causing the rupture } \\
\text { of cortical vessels during isolation }\end{array}$ \\
\hline $\mathbf{3}$ & Cerebral cortex is injured when the bone flap removed \\
\hline
\end{tabular}

Table 2. The evaluation of material adhesion.

The IR spectra of the studied samples from chitosan, chitosan/PEO $1 / 1$ wt $\%$, chitosan/PEO $7 / 3$ wt $\%$ were analyzed (Fig. 2). Data were obtained using a Fourier Transform Infrared (FTIR) Spectrometer Nicolet Nexus 450 (Thermo Scientific, USA) in the middle infrared range of 400 $4,000 \mathrm{~cm}^{-1}$.

Chitosan is a linear polysaccharide composed of a monomer $\mathrm{N}$-acetyl-1,4-b-D-glucopyranosamine. The IR spectra of native chitosan has specific absorption bands in the region of $3400 \mathrm{~cm}^{-1}$, belonging to $\mathrm{OH}$ hydrogen-bound molecular groups, as well as valent oscillations of $\mathrm{CH}$ in the region of $2900-2800 \mathrm{~cm}^{-1}$. The absorption in the region 1660 refers to $\mathrm{C}=0$ valent vibrations together with a small contribution of the deformation oscillations of $\mathrm{NH}_{2}$. The band in the region 1588 is actually referred to as $\mathrm{NH}_{2}$ deformation oscillations. The region of $1400-1300$ is specific of the deformation oscillations of $\mathrm{CH}$ molecular groups of [2729]. In the PEO film we observe an increase in the contribution of valence $\mathrm{CH}$ oscillations in the region of $2800-2900 \mathrm{~cm}^{-1}$ and deformation $\mathrm{CH}$ in the region of $1400-1300 \mathrm{~cm}^{-1}$. However, no frequency shifts in the formation of the chitosan-PEO complex are observed, indicating no intermolecular interactions between components of the polymer film [29-31].

Thus, from the proposed samples of composite biopolymer films based on chitosan, chitosan/PEO $7 / 3 \mathrm{wt} \%$ film was selected, because the surface roughness of this sample was maximum compared to others (according to electron microscopy. This film had less degree of swelling compared to native chitosan and almost did not differ from the swelling degree of chitosan/PE0 1/1 wt \%. The surface roughness of the scaffolds is critical for the selection of material, because in this case the colonization and proliferation of cells in the biopolymer material is more effective $[33,34]$.

Postoperative material of animals of the study group and samples of native DM of the control group were analyzed by IR spectroscopy. To analyze the IR absorption spectra, tissue samples up to $0.5 \mathrm{~mm}^{3}$ were excised from 5 sites of dural substitute implants from each animal. For control of experimental samples, similar tissue samples were excised from the intact dura mater over the opposite hemisphere in the same animals, where the injury was not modelled. Thin sections of postoperative tissue were prepared, which were dried at room temperature between two plates of fluorite glass $\left(\mathrm{CaF}_{2}\right)$ transparent in the IR region. Next, the obtained films on $\mathrm{CaF}_{2}$ base were placed in the cuvette chamber of the IFS 66 spectrometer (Bruker, USA) to analyze the absorption spectra.

The absorption spectra of native DM, scar tissue, and the substitutes from regenerating dura mater in a wide spectral range $\left(3400-800 \mathrm{~cm}^{-1}\right)$ were analyzed by infrared spectroscopy and a number of spectroscopic markers for analysis were determined. The most informative for the analysis is the region of absorption of amide bonds Amide I and Amide II in the range $1750-1480 \mathrm{~cm}^{-1}$. The formation of adhesion was macroscopically evaluated according to the Stryker system, table 2 [35].

After euthanasia of animals, tissues and implants were excised for histological examination. Tissue was fixed in serial 5-7-10\% solution of neutral formalin up to 24 hours and performed paraffin-embedded blocks in according standard technique. Serial 5-7 $\mu \mathrm{m}$ thick sections were prepared using a microtome HM430 (Microm, Germany) and stained hematoxylin and eosin. Histological sections were examined on a binocular microscope followed by photo documentation on a light optical photomicroscope Axiophot (Carl Zeiss, Germany) at magnifications objective $x 100$ and $x 200$, ocular $x 10$, and adapter $x 2$. Tissue sections were evaluated for local tissue changes, hemorrhage, cellular alterationin the cortex, the presence of an implant, newly formed dura mater or scar tissue.

Statistical data analysis was performed using the STATISTICA 10.0 software (StatSoft Inc., USA). Statistical significance of differences between groups was determined using the Mann-Whitney U-test. In all cases, the assumptions for the statistical significance of the obtained result were considered correct if the probability of the zero hypothesis was less than $0.05(p<0.05)$.

\section{RESULTS AND DISCUSSION}

In animals of the chitosan/PEO group, the remains of the film were not visualized. The surface of dura mater in the trepanation hole and outside did not differ. The fusion was detected on the periphery of the bone hole, but adhesions in the trepanation area were not detected (Fig. 3). The formation of adhesions between the defect of DM and the remains of the biopolymer film to assess the severity of adhesion was 0-1 points.

Three weeks after the surgery, when using chitosan-based film, the spectral characteristics show the presence of remains of this film in samples of DM from the corners and center of the trepanation window. In the sample of regenerating DM (green curve) the deviation is clearly visible in the area of $1587 \mathrm{~cm}^{-1}$, which definitely belongs to the film (Fig. 4). However, in this sample Amide II band is strongly pronounced at $1550 \mathrm{~cm}^{-1}$, as an indicator of protein tissue. This may indicate the degradation of the chitosan-based film and the repair of normal dural tissue.

It is shown that the IR spectroscopy allows to control the dynamics of dura mater regeneration. According to the analysis of IR absorption spectra, spectral markers of scar tissue, regenerating and intact DM were determined. Scar tissue differs significantly from the tissues of regenerating $\mathrm{DM}$, in particular, the presence of a band in the region $1739 \mathrm{~cm}^{-1}(\mathrm{C}=0)$, 


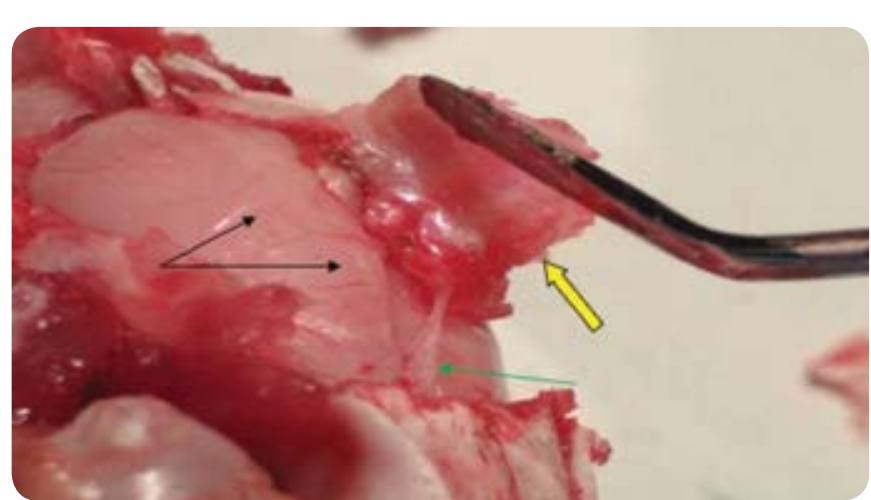

Aig. 3. Macroscopic picture of rats' skull in 3 weeks after duraplasty using biopolymer chitosan-based film. There are ill-defined fibrous adhesions on the periphery of the bone hole (green arrow); there are no adhesions in the area of the film implantation. Black arrows - the surface of dura mater in the surgery area. A yellow arrow - a bone fragment of the cranial vault with the trepanation hole (inner surface), the remaining bones of the cranial vault are removed.

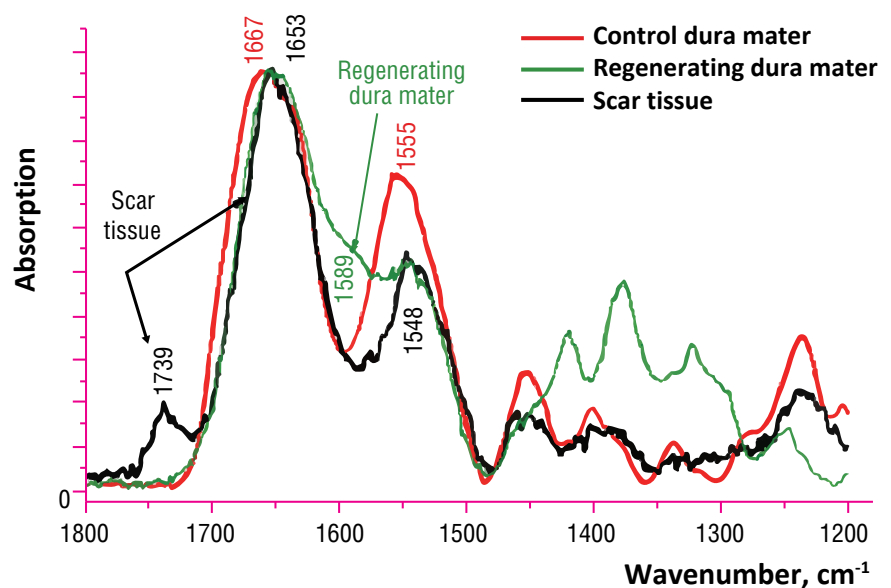

Fig. 4. Absorption spectra of dural tissue samples after implantation of chitosan-based film.

which is completely absent in the spectra of intact and regenerating DM. In addition, the ratio between the Amide I and Amide II bands differs by decreasing the intensity of Amide II and restriction the Amide I band compared to the sample of intact DM. In the sample of regenerating DM the presence of a band of oscillations of $\mathrm{NH}_{2}$ at $1589 \mathrm{~cm}^{-1}$ was identified, which refers to the absorption of the chitosan-based film, which is absent in the samples of intact DM and scar tissue. However, the presence of a band in the region of $1548 \mathrm{~cm}^{-1}$ (Amide II) indicates that there are cells on the film and suggests that regeneration processes occur.

The obtained data are confirmed by histological study. Replacement of the implant on the $21^{\text {st }}$ day after surgery with a biopolymer chitosanbased film occurred by forming a new fibrous connective tissue with a large number of hyperchromic fibroblasts and collagen fibers. Fibroblasts had both elongated and oval shape. In some cells (young forms of fibroblasts), rod-like pale-colored nuclei were observed (Fig. 5). The

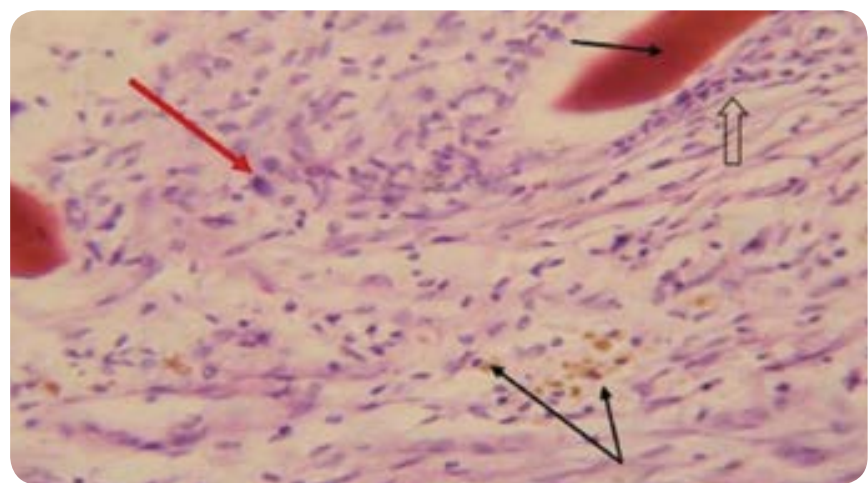

A Fig. 5. Photomicrograph of tissue specimen after duraplasty using biopolymer chitosan/PE0 7/3 wt\% film. Remains of chitosan (thin black arrows) among the colony of fibroblasts. Round cells young fibroblasts (red arrow), elongated cells - mature fibroblasts (transparent arrow). Hematoxylin-eosin staining; ob. x200, oc. x10, adapter $\mathrm{x} 2$.

expression of the bundles of collagen fibers and layers of the surrounding newly formed connective tissue was different. The bundles of fibers facing the cerebral surface from below were thinner than the bundles of fibers loca-lized on the outer surface. The edges of the defect of the dura mater and the newly formed fibrous tissue had no clear boundary. In addition, no inflammatory reactions were observed. The formation of weak adhesions between dura mater and brain is detected. The borderline brain tissue was normal.

The results of the study allow to positively evaluate the effectiveness of the application of the dura mater substitute based on chitosan/PEO $7 / 3$ wt $\%$ in rats. It can be assumed that the composite chitosan/PEO dural substitute first performs the function of a solid scaffold, and then PEO degrades or is washed out of the pores of chitosan, where further cells penetrate and the porous material is used to regenerate dura mater. The addition of PEO in the polymer composition led to a decrease in water absorption. The increase of PEO content did not significantly reduce the swelling of the materials.

The surface structure of the chitosan/PEO films depends on the content of polyethylene oxide. Thus, when the content of PEO is $30 \mathrm{wt} \%$, a rougher surface of the film is formed. When the content of PEO in the composite is $50 \mathrm{wt} \%$, there is a decrease in the roughness of the sample, the surface is more homogeneous. This is due to the penetration of PEO macromolecules into the supramolecular structure of chitosan with the simultaneous filling of cavities. The surface roughness of the implant may be important for improved adhesion to the native DM to seal the subdural space. In addition, when PEO is $30 \mathrm{wt} \%$, more pores remain for further penetration of cells.

The analysis of the IR spectrum of the chitosan/PEO $1 / 1 \mathrm{wt} \%$ and chitosan/PEO $7 / 3 w t \%$ films showed that with the increase of PEO concentration in the mixture the oscillations of amide groups of chitosan in the region of $1530 \mathrm{~cm}^{-1}$ and $1640 \mathrm{~cm}^{-1}$ gradually shifts to the region of higher waves. It can be assumed that the strong interactions of amide groups between chitosan molecules change to less strong interactions of the $\mathrm{N}-\mathrm{H}$ group of chitosan with unpaired electrons of oxygen atoms from polyethylene oxide macromolecules. 


\section{CONCLUSION}

1. Chitosan/polyethylene oxide biopolymer film (chitosan/PEO $7 / 3$ wt\%) is suitable for duraplasty under experimental conditions.

2. Morphological (macroscopic and histological) and spectroscopic (IR absorption) methods show the ability of chitosan/polyethylene oxide film to biodegradation.

3. The results of IR spectroscopy and histological data indicate that in the area of the biopolymer film implantation there are processes of normal regeneration of dural tissues, but scar tissue is not formed.

4. These studies allow us to conclude about the effectiveness of the chitosan/polyethylene oxide and its positive effect on the regeneration of dura mater in animals.

\section{REFERENCES}

1. MacEwan MR, Kovacs T, Osbun J, Ray Wilson Z. Comparative analysis of a fully-synthetic nanofabricated dura substitute and bovine collagen dura substitute in a large animal model of dural repair. Interdisciplinary Neurosurg. 2018; 13:145-150. D0I:10.1016/j.inat.2018.05.001.4

2. Matula C, Kjaersgaard L, Di leva A. Watertight dural closure in brain surgery: a simple model for training. J Neurol Surg A Cent Eur Neurosurg. 2014; 75(3):241-5. DOI:10.1055/s-0033-1342928.

3. Abuzayed B, Kafadar AM, Oguzoglu SA, Canbaz B, Kaynar MY. Duraplasty using autologous fascia lata reinforced by on-site pedicled muscle flap: technical note. J Craniofac Surg. 2009; 20(2): 435-8. D0I:10.1097/scs.0b013e31819b968f.

4. Hongtao Sun, Hongda Wang, Yunfeng Diao, Yue Tu, Xiaohong Li, Wanyong Zhao, et al. Large retrospective study of artificial dura substitute in patients with traumatic brain injury undergo decompressive craniectomy Brain Behav. 2018; 8(5):e00907. D0I: 10.1002/brb3.907.

5. Miyake S, Fujita A, Aihara H, Kohmura E. New technique for decompressive duraplasty using expanded polytetrafluoroethylene dura substitute--technical note. Neurol Med Chir (Tokyo). 2006; 46(2):104-6. D0I: 10.2176/nmc.46.104.

6. Schmalz P, Griessenauer C, Ogilvy CS, Thomas AJ. Use of an absorbable synthetic polymer dural substitute for repair of dural defects: a technical note. Cureus. 2018; 10(1):e2127. DOI:10.7759/cureus.2127.

7. Hoell T, Hohaus $C$, Huschak G, Beier A, Meisel HJ. Total dura substitute in the spine: double layer dural substitute made from polylactide layer and bovine pericardium. Acta Neurochir (Wien). 2007; 149(12):1259-62. D0l:10.1007/s00701-007-1414-8.

8. Narotam PK, Van Dellen JR, Bhoola K, Raidoo D. Experimental evaluation of collagen sponge as a dural graft. Br $\mathrm{J} N$ Neurosurg. 1993; 7(6):635-41. DOl:10.3109/02688699308995092.

9. Pettorini BL, Tamburrini G, Massimi L, Paternoster G, Caldarelli M, Di Rocco C. The use of a reconstituted collagen foil dura mater substitute in paediatric neurosurgical procedures - Experience in 47 patients Br J Neurosurg. 2010; 24(1):51-4. DOI: 10.3109/02688690903386991.

10. Azzam D, Romiyo P, Nguyen T, Sheppard JP, Alkhalid Y, Lagman C, et al. Dural Repair in Cranial Surgery Is Associated with Moderate Rates of Complications with Both Autologous and Nonautologous Dural Substitutes. World Neurosurg. 2018; 113:244-248. D0I:10.1016/j.wneu.2018.01.115.

11. Arutyunov Al, Meskhia NSh. Nekotorye aktual'nye voprosy plastiki defektov tverdoy mozgovoy obolochki [Some topical issues of the plasty of the defects of the dura mater]. Voprosy neyrokhirurgii - Neurosurgery Issues. 1972; 3: 3-9. [In Russian]

12. Kizmazoglu C, Aydin HE, Kaya I, Atar M, Husemoglu B, Kalemci O, et al. Comparison of Biomechanical Properties of Dura Mater Substitutes and Cranial Human Dura Mater : An In Vitro Study J Korean Neurosurg Soc. 2019; 62(6):635-642. D0l:10.3340/jkns.2019.0122.

13. Rosen CL, Steinberg GK, DeMonte F, Delashaw JB Jr, Lewis SB, Shaffrey ME, et al. Results of the prospective, randomized, multicenter clinical trial evaluating a biosynthesized cellulose graft for repair of dural defects. Neurosurgery. 2011; 69(5):1093-103. D0I: 10.1227/NEU.0b013e3182284aca.

14. Sandoval-Sanchez JH, Ramos-Zuniga $R$, de Anda SL, et al. A new bilayer chitosan scaffolding as a dural substitute: experimental evaluation. World neurosurgery. 2012; 77(3-4):577-582. D0I:10.1016/j.wneu.2011.07.007.

15. Lam FC, Kasper E. Augmented autologous pericranium duraplasty in 100 posterior fossa surgeries a retrospective case series. Neurosurg. 2012; 71. D0I:10.1227/ NEU.0b013e31826a8ab0.

16. Hoover DA, Mahmood A. Ossification of autologous pericranium used in duraplasty. Case report. J Neurosurg. 2001; 95(2):350-352. D0I:10.3171/jns.2001.95.2.0350.

17. Stevens EA, Powers AK, Sweasey TA, Tatter SB, Ojemann RG. Simplified harvest of autologous pericranium for duraplasty in Chiari malformation Type I. Technical note. J Neurosurg Spine. 2009; 11(1):80-83. D0I:10.3171/2009.3.SPINE08196.

18. Warren WL, Medary MB, Dureza CD, et al. Dural repair using acellular human dermis: experience with 200 cases: technique assessment. Neurosurg. 2000; 46(6):13911396. DOI:10.1097/00006123-200006000-00020

19. Verlee A, Mincke S, Stevens CV. Recent developments in antibacterial and antifungal chitosan and its derivatives. Carbohydr Polym. 2017; 164:268-283. D0I:10.1016/j. carbpol.2017.02.001.

20. Maslennikova LD. Polymer Composites [Polimerni kompoziti]. Kyiv, 2011. 300 p. [in Ukrainian]

21. Guo W, Guo Q, Zhang S, Li J. Manufacturing of artificial dura mater with chitosan polylactic acid. Chin J Clin Rehabil. 2005; 9:24-25.

22. Mengistu Lemma, Bossard SF, Rinaudo M. Preparation of Pure and Stable Chitosan Nanofibers by Electrospinning in the Presence of Poly (ethylene oxide). IJMS. 2016; 17(11):E1790.

23. Reed AM, Gilding DK. Biodegradable polymers for use in surgery—Poly(ethylene oxide)/poly(ethylene terephthalate) (PEO/PET) copolymers: 2. In vitro degradation. Polymer. 1981; 22:499-504.

24. Kumari A, Yadav SK, Yadav SC. Biodegradable polymeric nanoparticles based drug delivery systems. Colloids Surf B Biointerfaces. 2010; 75(1):1-18. D0I:10.1016/j. colsurfb.2009.09.001.

25. Zivanovic S, Li J, Davidson PM, Kit K. Physical, mechanical, and antibacterial properties of chitosan/PE0 blend films. Biomacromolecules. 2007; 8(5):1505-1510. DOI:10.1021/bm061140p.

26. Basu A, Krady JK, O'Malley M, Styren SD, DeKosky ST, Levison SW. The type 1 interleukin-1 receptor is essential for the efficient activation of microglia and the 
induction of multiple proinflammatory mediators in response to brain injury. J Neurosci. 2002; 22(14):6071-6082. D0I:10.1523/JNEUROSCI.22-14-06071.2002.

27. Dimzon IK, Knepper TP. Degree of deacetylation of chitosan by infrared spectroscopy and partial least squares. Int J Biol Macromol. 2015; 72:939-945. D0I:10.1016/j. ijbiomac.2014.09.050.

28. Kumirska J, Czerwicka M, Kaczyński Z, et al. Application of spectroscopic methods for structural analysis of chitin and chitosan. Mar Drugs. 2010; 8(5):1567-1636. DOI:10.3390/md8051567.

29. Paluszkiewicz C, Stodolak E, Hasik M, Blazewicz M. FT-IR study of montmorillonite-chitosan nanocomposite materials. Spectrochim Acta A Mol Biomol Spectrosc. 2011; 79(4):784-788. DOI: 10.1016/j.saa.2010.08.053.

30. Park HJ, Lee JS, Lee OJ, et al. Fabrication of microporous three-dimensional scaffolds from silk fibroin for tissue engineering. Macromol Res. 2014; 22:592-599. doi. org/10.1007/s13233-014-2083-0.

31. Yiin-Kuen Fuh, Shengzhan Chen, Jason S. C. Jang. Direct-write, Well-aligned Chitosan-Poly (ethylene oxide) Nanofibers Deposited via Near-field Electrospinning, Journal of Macromolecular Science, Part A: Pureand Applied Chemistry. 2012; 49(10):845-850. D0l:10.1080/10601325.2012.714676.

32. Zivanovic S, Li JP, Davidson M, Kit K. Physical, Mechanical, and Antibacterial Properties of Chitosan/PEO Blend Films. Biomacromolecules. 2007; 8:1505-1510. DOI:10.1021/bm061140p.

33. Katalinich M. Characterization of Chitosan Films for Cell CultureApplications. The University of Maine, 2001.

34. Foster LJ, Ho S, Hook J, Basuki M, Marçal H. Chitosan as a Biomaterial: Influence of Degree of Deacetylation on Its Physiochemical, Material and Biological Properties. PLoS One. 2015; 10(8):e0135153. DOl:10.1371/journal.pone.0135153.

35. Pre-Clinical Evaluation of Collagen Dura Substitutes in a Rabbit Duraplasty Model: DuraMatrix Suturable. 2015. https://cmf.stryker.com/assets/files/3i/duramatrixsuturable---white-paper.pdf

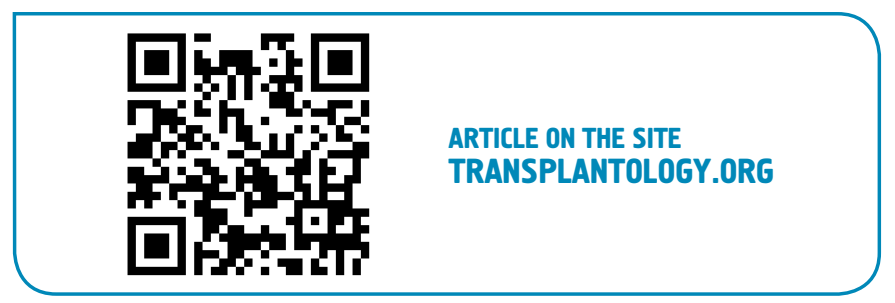

The authors declared no potential conflicts of interest with respect to the research, authorship, and/or publication of this article. 